\title{
Yeast-encapsulated essential oils: a new perspective as an environmentally friendly larvicide
}

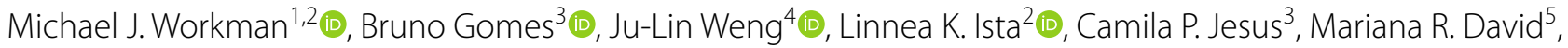
Marcelo Ramalho-Ortigao ${ }^{4}$ (D), Fernando A. Genta ${ }^{3,6}$, Scott K. Matthews ${ }^{7}$, Ravi Durvasula ${ }^{8}$ and Ivy Hurwitz ${ }^{1 *}$

\begin{abstract}
Background: Effective mosquito control approaches incorporate both adult and larval stages. For the latter, physical, biological, and chemical control have been used with varying results. Successful control of larvae has been demonstrated using larvicides including insect growth regulators, e.g. the organophosphate temephos, as well as various entomopathogenic microbial species. However, a variety of health and environmental issues are associated with some of these. Laboratory trials of essential oils (EO) have established the larvicidal activity of these substances, but there are currently no commercially available EO-based larvicides. Here we report on the development of a new approach to mosquito larval control using a novel, yeast-based delivery system for EO.
\end{abstract}

Methods: Food-grade orange oil $(\mathrm{OO})$ was encapsulated into yeast cells following an established protocol. To prevent environmental contamination, a proprietary washing strategy was developed to remove excess EO that is adsorbed to the cell exterior during the encapsulation process. The OO-loaded yeast particles were then characterized for $\mathrm{OO}$ loading, and tested for efficacy against Aedes aegypti larvae.

Results: The composition of encapsulated $\mathrm{O}$ extracted from the yeast microparticles was demonstrated not to differ from that of un-encapsulated EO when analyzed by high performance liquid chromatography. After lyophilization, the oil in the larvicide comprised 26-30 percentage weight (wt\%), and is consistent with the 60-65\% reduction in weight observed after the drying process. Quantitative bioassays carried with Liverpool and Rockefeller Ae. aegypti strains in three different laboratories presented $\mathrm{LD}_{50}$ of 5.1 (95\% Cl: 4.6-5.6) to 27.6 (95\% Cl: 26.4-28.8) mg/l, for L1 and L3/L4 mosquito larvae, respectively. $\mathrm{LD}_{90}$ ranged between 18.9 (95\% Cl: 16.4-21.7) mg/l (L1 larvae) to 76.7 (95\% Cl: 69.7-84.3) mg/l (L3/L4 larvae).

Conclusions: The larvicide based on $O O$ encapsulated in yeast was shown to be highly active $\left(\mathrm{LD}_{50}<50 \mathrm{mg} / \mathrm{l}\right)$ against all larval stages of Ae. aegypti. These results demonstrate its potential for incorporation in an integrated approach to larval source management of Ae. aegypti. This novel approach can enable development of affordable control strategies that may have significant impact on global health.

Keywords: Larvicide, Essential oil, Saccharomyces cerevisiae, Encapsulation

*Correspondence: ihurwitz@salud.unm.edu

${ }^{1}$ Center for Global Health, University of New Mexico Health Sciences Center, Albuquerque, NM, USA

Full list of author information is available at the end of the article

\section{Background}

Mosquito-borne diseases are a global threat to human health, implicated in over 1.2 million deaths annually [1]. Among these, those increasing at the fastest rate are the arboviruses dengue, chikungunya and Zika. In the absence of vaccines and effective treatment, public 
health responses have focused on preventing transmission by reducing vector populations. Unfortunately, these arboviruses are transmitted by the Aedes aegypti mosquito, a vector presenting formidable challenges to disease control. Aedes aegypti feeds during daylight hours, does not feed to repletion, and is primarily anthropophilic with preference for urban and exurban areas. Current approaches to control adult Ae. aegypti relying on insecticide spraying in urban areas pose risks to human and environmental health, and often select for mosquito resistance, making them ineffective and unsustainable [2].

Mosquito control using larvicides offers a potential solution to regional patterns of mosquito-borne disease transmission. Compared to sprayed insecticides targeting adult mosquitoes, larvicides are simpler and safer to implement. High kill rates can be achieved as larvae are confined to aquatic environments and are unable to evade control measures. However, synthetic larvicides currently in use, including carbamates, pyrethroids, organophosphates and organochlorides, exhibit one or more of four disadvantages: (i) toxicity to humans and other non-target species; (ii) degradation of the aquatic environment; (iii) high annual cost; and (iv) vulnerability to the evolution of target resistance. Alternatively, an ideal larvicide would have the following attributes: (i) non-toxic to humans and other non-target species; (ii) able to offer high kill rates over a short period of time; (iii) ecologically appropriate in application, with minimal alteration of the aquatic breeding environment; (iv) capable of retarding and/or responding to evolution of target species resistance; (v) inexpensive, and readily scalable; and (vi) designed to provide protection to the most vulnerable populations in areas with the highest rates of mosquito-borne diseases.

Essential oils (EO) are volatile oils with strong aromatic components imparting distinctive flavors or scents, and have a long history of commercial use, ranging from pharmaceuticals to flavor additives for foods [3]. While recognized as non-toxic to humans, these secondary metabolites are produced by plants for protection against pathogenic microorganisms and predator insects. EOs are highly complex natural mixtures, often containing between $20-60$ components. Of these, 2 or 3 components are present at distinctly high concentrations and, generally, it is these components that determine biological activity of the EO. Terpenes or terpenoids are common primary constituents of EOs, as are aromatic or aliphatic molecules.

In recent years, larvicidal activities of EOs from a number of plants $[4,5]$, including Citrus essential oils [6-9], Cryptomeria japonica (Japanese cedar) [10], Lippia sidoides (pepper-rosmarin) [11], Cinnamomum osmophloeum (cinnamon) [12], Syzygium aromaticum (clove) [13] and Cymbopogon citratus (lemongrass) [13, 14] have been reported. EOs have been shown to exert larvicidal effects through at least three different mechanisms: neurotoxicity $[15,16]$, growth inhibition, and interruption of metabolic pathways [17-19]. However, it should be noted that the relationship between larvicidal activity and the complex chemical composition of a particular EO can be difficult to determine, as interactions among compounds within each EO likely contribute to its killing properties. Further, the combined action of all the components within a particular EO may not only provide a synergistic increase in effectiveness, but likely also prevents the evolution of resistance [18].

Although the efficacy of EOs against larvae of many mosquito species has been demonstrated, there are currently no commercial EO-based larvicides available. While non-toxic to humans and other non-target species at low concentration [20], introduction of large amounts of EO into an aquatic larval environment is likely to disrupt the microbial environment and harm non-target species. In addition, dispersed oils are vulnerable to rapid degradation by UV radiation. The challenge is to deliver essential oils to environments containing mosquito larvae in an efficient, efficacious, and sustainable manner that does not adversely impact the aquatic ecosystem.

Saccharomyces cerevisiae (bakers' yeast) has long been recognized as a viable biocompatible and biodegradable container for a variety of exogenous compounds [21]. Both hydrophobic and hydrophilic food ingredients and pharmaceuticals have been encapsulated into yeast cells for protection, masking, and targeted drug delivery. Incorporating EOs into yeast is accomplished through a simple process using heat and agitation [22]. Once the EO enters the cell, the yeast becomes nonviable. The thick outer envelope of the yeast cell, however, remains intact, and sequesters the oil from the surrounding environment. In this respect $S$. cerevisiae is an ideal field delivery vehicle: it preserves the activity of its payload (EO) while losing the capacity to replicate, and thus to impact aquatic ecosystems. The efficacy of this approach is further facilitated by the fact that mosquito larvae can readily digest $S$. cerevisiae [23]. The cell wall of yeast cells is rich in $\beta-1,3$-glucan, a polysaccharide. Larvae have intestinal enzymes specialized for the digestion of $\beta-1,3$ glucans and are able to rapidly break down ingested yeast cell membranes [23]. Further, one of the WHO recommended food sources for rearing of mosquito larvae in laboratory settings is S. cerevisiae [24].

In this article we describe the development of a novel larvicide consisting of food-grade orange oil (OO) encapsulated into yeast cells. This approach opens a new perspective for the development of a more environmentally 
friendly larvicide. The defining feature of this formulation is a proprietary washing protocol developed to remove excess EO on the outside of these particles, thereby limiting the amount of $\mathrm{EO}$ dispersed into the environment. The microparticles were characterized for EO loading and tested for their efficacy against Ae. aegypti larvae.

\section{Methods}

\section{Larvicide synthesis}

Larvicide was synthesized by encapsulation of Citrus sinensis EO (orange oil, California origin, Sigma-Aldrich, St. Louis, USA) in S. cerevisiae (Red Star fresh baker's yeast). The encapsulation method is based on an existing process $[22,25]$, but was optimized to increase encapsulation efficiency for each of the EO tested. A proprietary method (U.S. Provisional Application No 62/752,512) was developed to effectively wash all residual oil from the outside of the microcapsules.

The components used in synthesis of the EO-based larvicide used in this study are orange oil, fresh yeast, and water at ratios of 1:5:16 by weight. Components were placed in a baffled flask and agitated overnight at $40{ }^{\circ} \mathrm{C}$. The solution was then centrifuged, and the supernatant discarded. The larvicide was washed to remove residual oils, then frozen and lyophilized. Larvicide aliquots were rehydrated before use. Similar protocols were used for the encapsulation of essential oils from Australian white cypress, cinnamon leaf, clove bud, lemongrass and thyme.

\section{Analysis of encapsulated oil}

Oil composition analysis and quantification of encapsulated $\mathrm{OO}$ was carried out using high performance liquid chromatography (HPLC) on an Agilent 1100 with a temperature-controlled column and UV detector using an Agilent ZORBAX Rx $80 \AA$ C18 column $(4.6 \times 250 \mathrm{~mm}$ with $5 \mu \mathrm{m}$ particle size). Analysis was performed isocratically at $40{ }^{\circ} \mathrm{C}$ using $80 \%$ acetonitrile and $20 \%$ water mobile phase with flow rate of $1.0 \mathrm{ml} / \mathrm{min}$ and UV detection at $214 \mathrm{~nm}$. Full separation of EO components using these conditions were obtained after 14 mins of runtime. Between analyses, the column was washed at $1.5 \mathrm{ml} / \mathrm{min}$ with methanol for $4 \mathrm{~min}$, rinsed using a linear gradient from aqueous $1 \%$ acetic acid to acetonitrile over $5 \mathrm{~min}$, followed by equilibration at the isocratic analysis ratio for $10 \mathrm{~min}$. For quantification of OO, standard calibration curves for myrcene (Sigma-Aldrich), $\gamma$-terpinene (SigmaAldrich), and D-limonene (Sigma-Aldrich) at concentrations of 5-1000 mg/l were generated. Retention times for each component were $9.7 \mathrm{~min}, 11.8 \mathrm{~min}$ and $12.3 \mathrm{~min}$, respectively.

Encapsulated oils were extracted from microcapsules by bead milling. Two hundred and fifty $\mathrm{mg}$ of rehydrated microcapsules were combined with 300 $330 \mathrm{mg}$ of $0.5 \mathrm{~mm}$ glass beads and $1.0 \mathrm{ml}$ ethanol in a $15 \mathrm{ml}$ conical vial. The sample was vortexed vigorously for $2 \mathrm{~min}$, centrifuged, and supernatant recovered. A second extraction with another $1.0 \mathrm{ml}$ of ethanol was then performed. The two extracts were combined and filtered through a $0.2 \mu \mathrm{m}$ PTFE membrane syringe filter (VWR) before HPLC analysis.

\section{Imaging}

Imaging was performed on microcapsules labeled with Nile Red (Sigma-Aldrich). Labeling was performed by adding $0.1 \mathrm{ml}$ of $1 \mathrm{mg} / \mathrm{ml}$ Nile Red in DMSO to $1 \mathrm{ml}$ of larvicide suspension (diluted to $10 \%$ microcapsules by weight) with shaking at $37{ }^{\circ} \mathrm{C}$ for $30 \mathrm{~min}$. Labeled larvicide was washed twice with $10 \mathrm{ml}$ distilled (DI) water after labeling. Wet mounts with labeled cells were prepared using Fluoromount ${ }^{\mathrm{TM}}$ (Thermo Fisher Scientific, Waltham, USA) and imaged on a Zeiss AxioObserver microscope equipped with a Hamamatsu Flash4.0v2 sCMOS Camera. Bright field, differential interference contrast (DIC), and fluorescence images were captured.

\section{Larvicide testing}

Larvicidal activity was tested at the University of New Mexico (UNM) and Uniformed Services University of the Health Sciences (USU) using Ae. aegypti (Liverpool strain) larvae. Similar experiments were performed at Laboratório de Bioquímica e Fisiologia de Insetos, Instituto Oswaldo Cruz (IOC-Fiocruz) using Ae. aegypti (Rockefeller strain) larvae (eggs provided by Laboratório de Fisiologia e Controle de Artrópodes Vetores, IOC-Fiocruz). Eggs were hatched in deionized water (DI) $28{ }^{\circ} \mathrm{C}$ with fish food provided ad libitum. Once they reached the desired stage, larvae were placed into cups containing $100 \mathrm{ml}$ DI water and measured concentrations of larvicide. Larvicide quantitative bioassays were performed using 1st (L1), 2nd (L2), 3rd (early L3 and L3) and late 3rd/early 4th (L3/L4) instar larvae at three different insectaries. Each cup contains 25 larvae and each dose was replicated on 4 cups for a total of 100 larvae per trial. Larvicide tests were performed at $28{ }^{\circ} \mathrm{C}$. Live and dead larvae were counted after $24 \mathrm{~h}$ of larvicide exposure to determine mortality rate at each concentration. All experiments were performed a minimum of 3 times at each site. Mortality curves and lethal doses (LD) values were calculated using the logit generalized linear model implemented in $\mathrm{R}$. All lethal doses are presented with confidence interval at $95 \%(95 \% \mathrm{CI})$. 


\section{Results}

\section{Larvicide analysis}

Micrographs of larvicide particles labeled with Nile Red show that the individual cells are intact and EO is incorporated within the cells (Fig. 1). Cells without encapsulated oil showed no fluorescence when imaged using a TRITC filter (Ex/Em 557/576) under the same exposure settings as cells with encapsulated oil. Average diameter of the yeast cells was $6.2 \mu \mathrm{m}$. Following OO encapsulation, this diameter decreased to an average of $4.4 \mu \mathrm{m}$.

Analysis of OO by HPLC before encapsulation yielded a composition of $89.6 \% \mathrm{D}$-limonene, $2.4 \%$ myrcene, and $1.6 \% \gamma$-terpinene with $8.2 \%$ other minor components, which is consistent with previously reported compositions [26, 27]. After encapsulation, the extracted oil composition was similar: $89.7 \% \mathrm{D}$-limonene, $2.2 \%$ myrcene, and $1.7 \% \gamma$-terpinene, as seen in Fig. 2. After encapsulation and washing, but before drying, the oil loading in the larvicide was measured to be from 9.4-10.6 wt\%, exhibiting a small amount of batch to batch variability. After lyophilization, the oil loading in the larvicide was $26-30 \mathrm{wt} \%$, which is consistent with the $60-65 \%$ reduction in weight observed after the drying process. No significant changes in oil loading, oil composition or

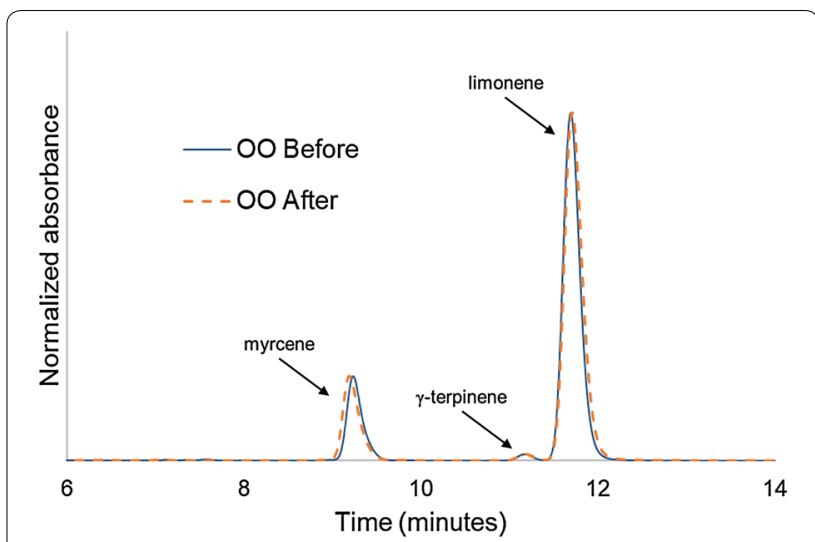

Fig. 2 HPLC chromatogram of orange oil (OO) before encapsulation and after extraction from yeast microparticles

larvicidal efficacy were observed with lyophilized samples stored at $4{ }^{\circ} \mathrm{C}$ for 6 months.

\section{Larvicide efficacy}

Mortality at $24 \mathrm{~h}$ was observed to be dose dependent at every instar, with lethal dose (LD) as shown in Fig. 3 and Table 1. The $\mathrm{LD}_{50}$ and $\mathrm{LD}_{90}$ increased sharply as larvae matured, e.g. from 5.1 and $18.9 \mathrm{mg} / \mathrm{l}$, respectively, for
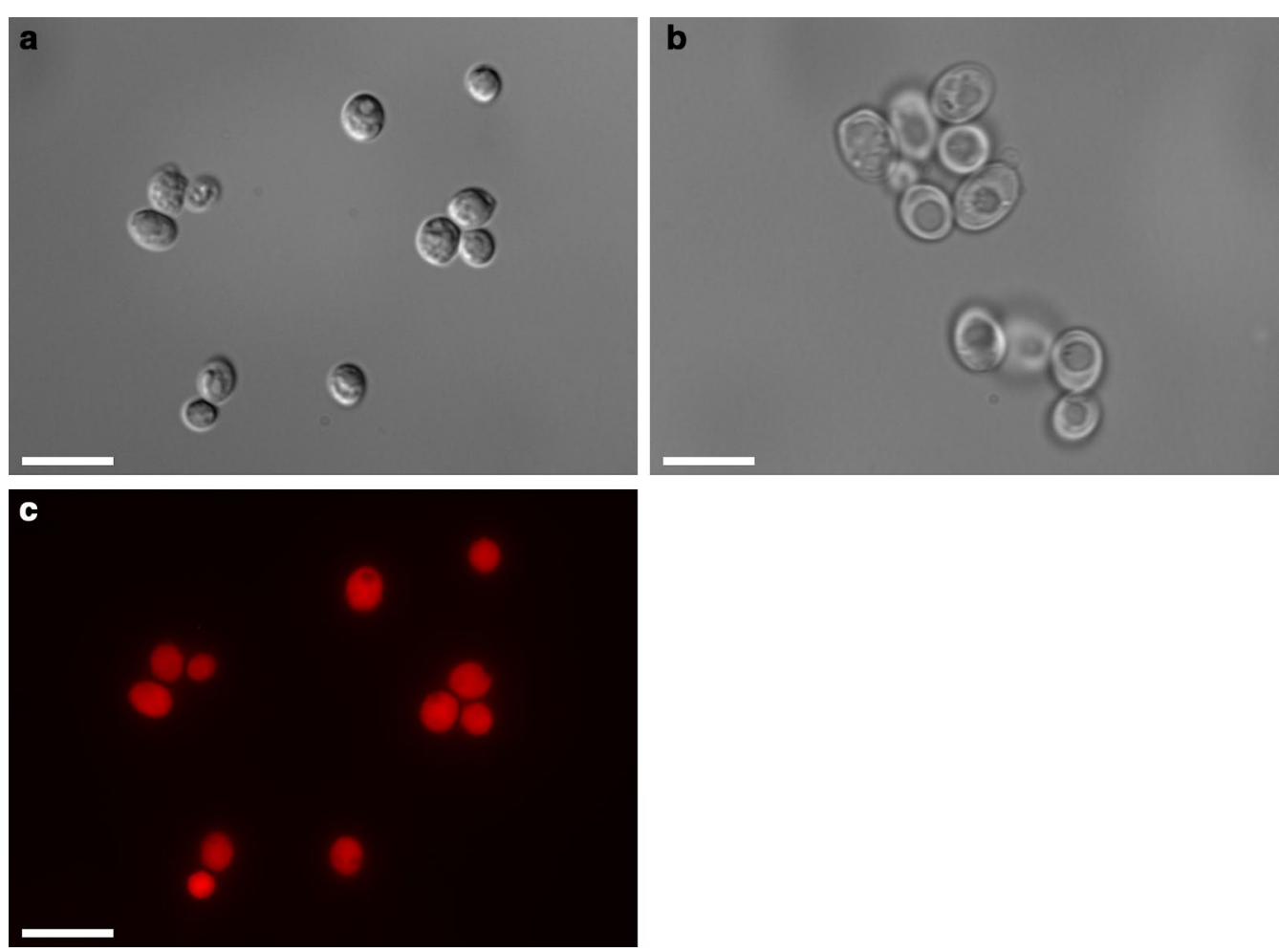

Fig. 1 Micrographs of cells with and without encapsulated orange oil (OO). DIC images of cells with (a) and without oil (b). c Fluorescence of cells with oil using the TRITC filter. Cells without oil exhibited no visible fluorescence under these imaging conditions (not shown). Scale-bars: $10 \mu \mathrm{m}$ 


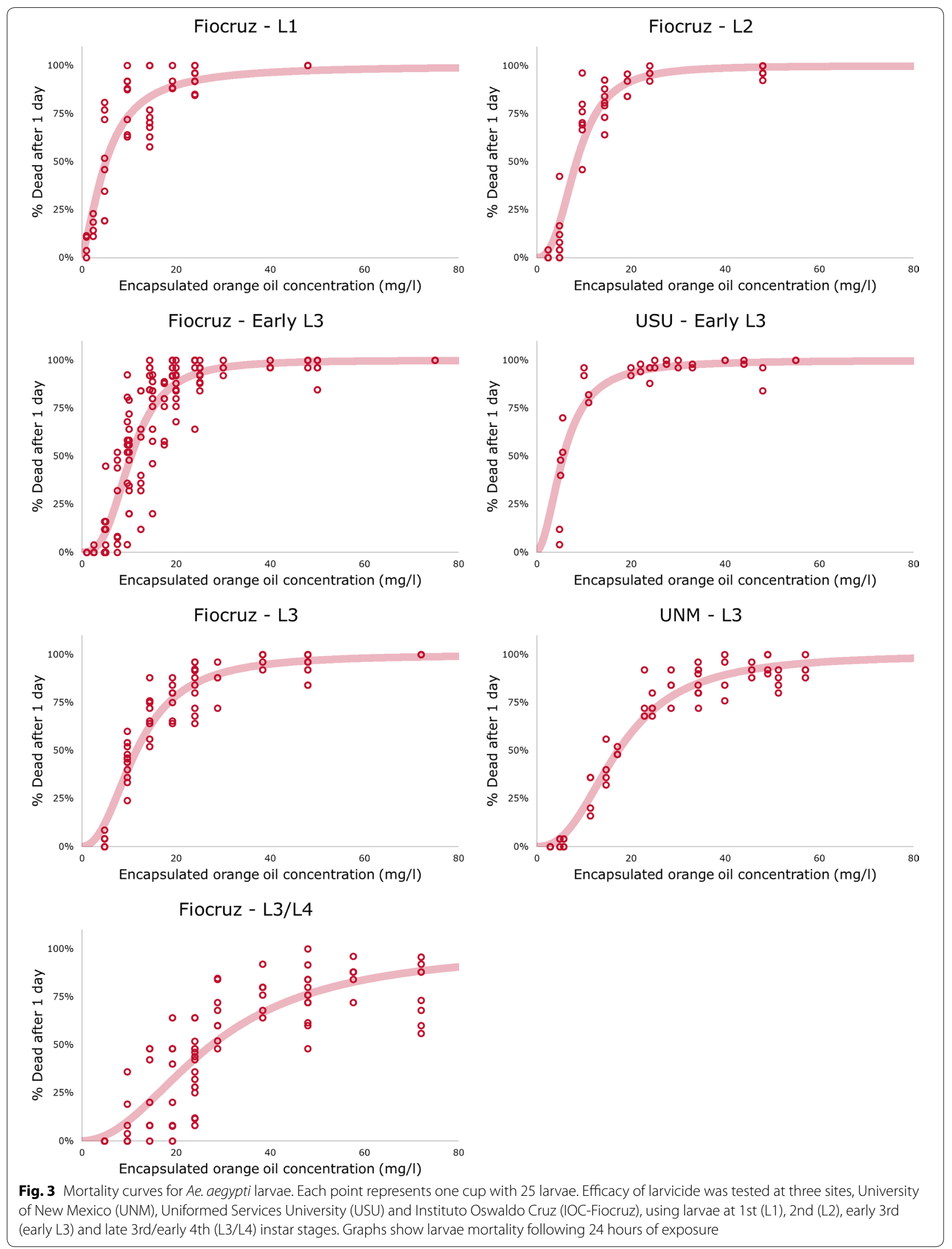


Table 1 Computed $\mathrm{LD}_{50}$ and $\mathrm{LD}_{90}$ values of yeast-encapsulated orange oil against various Ae. aegypti larval stages

\begin{tabular}{llllllll}
\hline & \multicolumn{1}{l}{ Insect stage } & & & & & \\
\cline { 2 - 7 } & L1 & L2 & Early L3 & Early L3 & L3 & L3 & L3/L4 \\
\hline Testing institution & Fiocruz & Fiocruz & Fiocruz & USU & Fiocruz & UNM & Fiocruz \\
$\mathrm{LD}_{50}(95 \% \mathrm{Cl})$ & $5.1(4.6-5.6)$ & $8.4(7.9-9.0)$ & $10.4(10.1-10.8)$ & $5.6(5.0-6.3)$ & $11.6(10.9-12.3)$ & $17.3(16.3-18.3)$ & $27.6(26.4-28.8)$ \\
$\mathrm{LD}_{90}(95 \% \mathrm{Cl})$ & $18.9(16.4-21.7)$ & $17.8(16.2-19.7)$ & $21.0(20.0-21.9)$ & $15.3(13.6-17.2)$ & $28.4(26.2-30.9)$ & $40.3(37.2-43.7)$ & $76.7(69.7-84.3)$ \\
$n$ & 1234 & 2016 & 4210 & 1200 & 1772 & 1600 & 2409 \\
\hline
\end{tabular}

Notes: Testing was performed using Ae. aegypti Rockefeller strain larvae at Instituto Oswaldo Cruz (IOC-Fiocruz), and on Ae. aegypti Liverpool strain at the Uniform Services University (USU) and the University of New Mexico (UNM). Variation in LD values may reflect difference between the two larval strains used. LD values are in $\mathrm{mg} / \mathrm{l}$ of orange oil. This table is a compilation of all experiments performed at the three sites, with $\mathrm{n}$ representing the total number of insects tested at each larval stage. While there were some differences between the $\mathrm{LD}_{50}$ and $\mathrm{LD}_{90}$ values measured in different research institutes, these measurements fall in the same order of magnitude

L1 larvae to 27.6 and $76.7 \mathrm{mg} / \mathrm{l}$, respectively, for L3/L4 larvae (Table 1). Variation seen between $\mathrm{LD}_{50}$ and $\mathrm{LD}_{90}$ values may be attributed to the two different laboratory strains of Ae. aegypti used at the three study locations. Overall however, these values show a maximum difference of 1.85 -fold ( $\mathrm{LD}_{50}$ for early $\mathrm{L} 3$ larvae) between sites (Table 1).

Encapsulated Australian white cypress, cinnamon leaf, clove bud, lemongrass and thyme oils were also tested for larvicidal activities. The efficacy of this selection of EOs were previously reported by others $[4,28]$. Qualitative microscopy examination of these EO encapsulated cells suggested that similar volumes of encapsulated EO were incorporated into the yeast cells. Larvae were fed encapsulated EO corresponding to $3 \times$ the $\mathrm{LD}_{90}$ for $\mathrm{OO}$. After $24 \mathrm{~h}$ of treatment, mortality of less than $10 \%$ was observed with each of these encapsulated EO (data not shown).

\section{Discussion}

The larvicide based on yeast-encapsulated OO was highly active $\left(\mathrm{LD}_{50}<50 \mathrm{mg} / \mathrm{l}\right)$ against all Ae. aegypti larval instars (Table 1). $\mathrm{LD}_{50}$ is the standard measure for larvicidal activity of natural products such as EO, but effect thresholds can vary [29]. The $\mathrm{LD}_{50}$ from bioassays carried out in the three laboratories involved in this study are consistent and ranged from 5.1 to $27.6 \mathrm{mg} / \mathrm{l}$ for $\mathrm{L} 1$ to $\mathrm{L} 3 /$ L4 larvae respectively. These results confirm our preparation as an active larvicide, with a reproducible mode of delivery [30-32]. This is particularly important due to the high variation in cidal activity of orange oil described in previous studies, including variations in $\mathrm{LD}_{50}$ from $<100 \mathrm{mg} / \mathrm{l}$ against mosquito larvae $[5,7,30,33]$ to a complete lack of larvicidal activity $[6,8,34]$. In some studies, these differences may be attributed to the methodology used for extraction of the EO, as in the case of larvicidal activities reported for hexane extracts of Citrus limetta compared to petroleum ether extracts of the same plant [35].
These results of our bioassays were obtained using two laboratory strains of mosquitoes (Liverpool and Rockefeller) that have been used as reference strains for resistance assays, and as such, may be more sensitive to xenobiotics than insects found in the wild [36]. The efficacy of the $\mathrm{OO}$-yeast particles on larvae progeny $(\mathrm{F}<10)$ from strains of field-caught mosquitoes resistant or susceptible to a variety of commercially used larvicides are currently being evaluated in the laboratory as well as under semifield conditions at various sites in Brazil. The persistence and impact of this larvicide on non-target organisms, including Artemia, Daphnia and Macrobrachium amazonicum (Amazon River prawn), are also being assessed in the laboratory.

At the onset of our studies, multiple oils were screened for larvicidal activities to determine the best candidate(s) for encapsulation optimization and activity trials. Australian white cypress, cinnamon leaf, clove bud, lemongrass and thyme oils were selected as their primary components differ from those of orange oil. Further, the reported $\mathrm{LD}_{50}$ for each of these $\mathrm{EO}$ ranges between $0.7-69 \mathrm{mg} / \mathrm{l}$ [4]. Their lack of efficacy when administered as encapsulated consumables (data not shown) may be related to different mechanisms of action for these compounds when ingested by larvae, as opposed to being used as contact agents, as in all previous studies [15-19]. Investigation into the mechanism of action after ingestion of encapsulated OO by larvae is ongoing.

Our initial bioassays demonstrated high variability of $\mathrm{LD}_{50}$ for all encapsulated EO in a single trial. We hypothesized that presence of EO on the exterior surface of the microcapsules allowed two known properties of these materials to manifest: (i) acting as contact agents which rapidly kill larvae; and (ii) acting as repellents preventing the larvae from eating the microcapsules, even in the absence of other food sources. In response, we developed a washing protocol to remove residual oil for the outside of the yeast particles. Upon implementing this protocol results for larvicidal activity became reproducible both 
within individual replicates and across different batches. Importantly, results obtained in three different research institutes across the Americas evinced high reproducibility. After our optimized washing process, HPLC analysis of supernatant from concentrated larvicide solution (50 wt $\%$ cells $\sim 50,000 \mathrm{mg} / \mathrm{l}$ encapsulated $\mathrm{OO}$ ) showed no evidence of $\mathrm{D}$-limonene, myrcene, or $\gamma$-terpinene (data not shown).

Interestingly, higher $\mathrm{LD}_{50}$ and $\mathrm{LD}_{90}$ was observed in L3/L4 larvae. Lower mortality rates in later stage insects may be related to reduced feeding in late L4 mosquito larvae. It has been reported that Ae. aegypti larvae, after reaching a critical body mass, stop eating and start preparation to metamorphosis if exposed to stressing factors, like xenobiotics or food with low nutritional value [37]. In this respect, the EO-yeast particles might be inducing pupation in L4 larvae, and that is consistent with the hypothesis that ingestion of the larvicide is an important step in its mechanism of action.

In integrated mosquito control programs, larval source management (LSM) is recognized as successful when it prevents completion of immature mosquito development [38]. The highly anthropophilic Ae. aegypti is an urban mosquito living in close proximity to humans and breeding predominantly in human-made containers. These "container-inhabiting" mosquitoes, will breed in almost any aquatic receptacle, from puddles found in flower pots, tires, bottles, gutters to pools of water in communal cisterns and catch basins. Efforts to eliminate $A e$. aegypti breeding sites are often labor intensive and may require coordination of large numbers of workers, as well as substantial public engagement to sustain community participation in the control efforts $[39,40]$. This is further complicated by the fact that eggs of Ae. aegypti can withstand desiccation, surviving without water for several months and hatching following the next rainfall [41]. As an alternative, application of organophosphate-based larvicides is costly, harmful to the environment and many strains of Ae. aegypti exhibit well documented resistance to these compounds [42]. Similarly, the bioinsecticides Bacillus thuringiensis israelensis (Bti) and Bacillus sphaericus (Bs) are effective against different species of mosquito larvae under laboratory and environmental settings [42], but their stability is reduced under sunlight and heat exposure $[43,44]$. Thus, development of new insecticides effective in tropical climate where mosquito-transmitting diseases are important public health problems, is an urgent need.

The use of insect growth regulators (e.g. pyriproxyfen), entomopathogenic fungi [45] and EO [4] as larvicides have also been reported. However, environmental dissemination of these larvicides continues to be a major obstacle. For pyriproxyfen, this appears to be feasible through auto-dissemination by adult mosquitoes [46, 47]. For EOs, one of the main issues faced for its successful application relates to its' solubility in an aqueous environment. Ferreira et al. [48], for example, overcame this issue by entrapping orange oil into an in situ gelling nanostructured surfactant system, which allowed for improved solubility and contact larvicide activity. To control aphid infestations, Akvetsou et al. [49] encapsulated pennyroyal EO into plasmolyzed yeast cells. These investigators demonstrated a "burst" release of trapped EO from these ruptured yeast cells into the surrounding environment within 30 mins of application. Here, we report on the development of OO laden yeast particles as an ingested larvicide, thereby limiting its impact on non-yeast consuming species. Moreover, the primary components for the synthesis of our larvicide (fresh baker's yeast and orange oil) are certified food-grade and recognized as environmentally friendly. This technology has the additional advantage of easy adaptability to new formulations depending on the local context e.g. use of alternative essential oils.

\section{Conclusions}

Our novel larvicide based on orange oil encapsulated in yeast was effective against L1-L4 Ae. aegypti larvae. Here we have demonstrated an approach that sequesters the cidal compound from the environment and delivers it unmodified to a target species. This approach may provide a solution to the long-standing problem of controlling vector populations with minimal harm to non-target organisms. While the approval and eventual deployment of this larvicide is dependent upon multiple variables, our low-cost product has the potential to function as an initial step in the development of a more environmentally friendly platform technology for the control of multiple vector species.

\section{Abbreviations \\ DI: deionized; DIC: differential interference contrast; EO: essential oil; IOC- Fiocruz: Instituto Oswaldo Cruz; HPLC: high performance liquid chromatogra- phy; LSM: larvae source management; UNM: University of New Mexico; USU: Uniformed Services University; OO: orange oil; wt\%: percentage weight.}

\section{Acknowledgements}

We wish to thank UNM Center for Biomedical Engineering for lab space and use of their HPLC; and the Laboratório de Fisiologia e Controle de Artrópodes Vetores (IOC-Fiocruz, Rio de Janeiro, BR) for providing eggs of Ae. aegypti (Rockefeller) for use in experiments described. Images in this paper were generated in the University of New Mexico \& Cancer Center Fluorescence Microscopy Shared Resource, funded as detailed in http://hsc.unm.edu/crtc/ microscopy/acknowledgement.shtml.

\section{Disclaimer}

MRO is an employee of the U.S. Government. Title 17 U.S.C. §101 defines a U.S. Government work as a work prepared by a military service member or employee of the U.S. Government as part of that person's official duties. The opinions and assertions expressed herein are those of the author(s) and do 
not necessarily reflect the official policy or position of the Uniformed Services University or the Department of Defense.

\section{Authors' contributions}

This study was originally conceived by SKM, RD and IH. MJW worked with LKI and SKM on the development and optimization of encapsulation protocols, and with $\mathrm{H}$ on larvicide bioassays at UNM. J-LW and MRO performed larvicide bioassays at USU. BG, CPJ, MRD and FAG performed larvicide bioassays at Fiocruz. MJW and BG performed the statistical analysis and wrote the manuscript. LKI, MRD, MRO, FAG, SKM, RD and IH revised the manuscript. All authors read and approved the final manuscript.

\section{Funding}

This study was funded through contract \#200-2017-93140 with the Centers for Disease Control and Prevention. The funder had no role in study design, data collection and analysis, decision to publish or preparation of the manuscript.

\section{Availability of data and materials}

Data supporting the conclusions of this article are included within the article. The protocol used for washing of the encapsulated larvicide is proprietary (U.S. Provisional Application No. 62/752,512). The use of yeast-encapsulated EO as a novel larvicide was published as WO2016168837, and is available at https:// patentscope.wipo.int/beta/en/detail.jsf?docld=WO2016168837\&_cid=B16K48SGY-75509-1 (Accessed 12/16/2019).

\section{Ethics approval and consent to participate}

Not applicable.

\section{Consent for publication}

Not applicable.

\section{Competing interests}

The authors declare that they have no competing interests.

\section{Author details}

${ }^{1}$ Center for Global Health, University of New Mexico Health Sciences Center, Albuquerque, NM, USA. ${ }^{2}$ Department of Chemical and Biological Engineering University of New Mexico, Albuquerque, NM, USA. ${ }^{3}$ Laboratório de Bioquímica e Fisiologia de Insetos, Instituto Oswaldo Cruz (IOC-Fiocruz), Rio de Janeiro, Brazil. ${ }^{4}$ Department of Preventive Medicine and Biostatistics, Uniformed Services University, Bethesda, MD, USA. ${ }^{5}$ Laboratório de Mosquitos Transmissores de Hematozoários, Instituto Oswaldo Cruz (IOC-Fiocruz), Rio de Janeiro, Brazil. ${ }^{6}$ Instituto Nacional de Ciência e Tecnologia em Entomologia Molecular, Rio de Janeiro, Brazil. ${ }^{7}$ Department of General Preventive Medicine, School of Medicine and Dentistry, University of Rochester, Rochester, NY, USA. ${ }^{8}$ Loyola University Stritch School of Medicine, Maywood, IL, USA.

Received: 20 June 2019 Accepted: 29 December 2019

Published online: 13 January 2020

\section{References}

1. Weaver SC, Reisen WK. Present and future arboviral threats. Antiviral Res. 2010;85:328-45.

2. Hemingway J. Resistance: a problem without an easy solution. Pesticide Biochem Phys. 2018;151:73-5.

3. Bakkali F, Averbeck S, Averbeck D, Idaomar M. Biological effects of essential oils-a review. Food Chem Toxicol. 2008:46:446-75.

4. Pavela R. Essential oils for the development of eco-friendly mosquito larvicides: a review. Ind Crop Prod. 2015;76:174-87.

5. Vera SS, Zambrano DF, Méndez-Sanchez SC, Rodríguez-Sanabria F, Stashenko EE, Duque Luna JE. Essential oils with insecticidal activity against larvae of Aedes aegypti (Diptera: Culicidae). Parasitol Res. 2014;113:2647-54.

6. Murugan K, Kumar PK, Kovendan K, Amerasan D, Subrmaniam J, Hwang J-S. Larvicidal, pupicidal, repellent and adulticidal activity of Citrus sinensis orange peel extract against Anopheles stephensi, Aedes aegypti and Culex quinquefasciatus (Diptera: Culicidae). Parasitol Res. 2012;111:1757-69.

7. Araujo AFO, Ribeiro-Paes JT, Deus JT, Cavalcanti SCH, Nunes RS, Alves PB, et al. Larvicidal activity of Syzygium aromaticum (L.) Merr and Citrus sinensis (L.) Osbeck essential oils and their antagonistic effects with temephos in resistant populations of Aedes aegypti. Mem Inst Oswaldo Cruz. 2016;111:443-9.

8. Warikoo R, Ray A, Sandhu JK, Samal R, Wahab N, Kumar S. Larvicidal and irritant activities of hexane leaf extracts of Citrus sinensis against dengue vector Aedes aegypti L. Asian Pac J Trop Biomed. 2012;2:152-5.

9. Campolo O, Romeo FV, Algeri GM, Laudani F, Malacrino A, Timpanaro $\mathrm{N}$, et al. Larvicidal effects of four citrus peel essential oils against the arbovirus vector Aedes albopictus (Diptera: Culicidae). J Econ Entomol. 2016;109:360-5.

10. Mdoe FP, Cheng SS, Lyaruu L, Nkwengulila G, Chang ST, Kweka EJ. Larvicidal efficacy of Cryptomeria japonica leaf essential oils against Anopheles gambiae. Parasit Vectors. 2014;7:426.

11. Carvalho AF, Melo VM, Craveiro AA, Machado MI, Bantim MB, Rabelo EF. Larvicidal activity of the essential oil from Lippia sidoides Cham. against Aedes aegypti linn. Mem Inst Oswaldo Cruz. 2003;98(4):569-71.

12. Cheng SS, Liu JY, Tsai KH, Chen WJ, Chang ST. Chemical composition and mosquito larvicidal activity of essential oils from leaves of different Cinnamomum osmophloeum provenances. J Agric Food Chem. 2004;52:4395-400.

13. Soonwera M, Phasomkusolsil S. Effect of Cymbopogon citratus (lemongrass) and Syzygium aromaticum (clove) oils on the morphology and mortality of Aedes aegypti and Anopheles dirus larvae. Parasitol Res. 2016;115:1691-703.

14. Sukumar K, Perich MJ, Boobar LR. Botanical derivatives in mosquito control: a review. J Am Mosq Control Assoc. 1991;7:210-37.

15. Enan E. Insecticidal activity of essential oils: octopaminergic sites of action. Comp Biochem Physiol C Toxicol Pharmacol. 2001;130:325-37.

16. Lopez MD, Pascual-Villalobos MJ. Mode of inhibition of acetylcholinesterase by monoterpenoids and implications for pest control. Ind Crop Prod. 2010;31:284-8.

17. Reynolds SE. The cuticle, growth and moulting in insects: the essential background to the action of acylurea insecticides. Pesticide Sci. 1987;20:131-46.

18. Rattan RS. Mechanism of action of insecticidal secondary metabolites of plant origin. Crop Prot. 2010;29:913-20.

19. Belzile AS, Majerus SL, Podeszfinski C, Guillet G, Durst T, Arnason JT. Dillapiol derivatives as synergists: structure-activity relationship analysis. Pesticide Biochem Phys. 2000;66:33-40.

20. Pavela R, Benelli G. Essential oils as ecofriendly biopesticides? Challenges and constraints. Trends Plant Sci. 2016;21:1000-7.

21. Shank JL. Encapsulating eg dyes, drugs, chemicals, adhesives etc-using microorganisms eg fungi, yeast by forming large fat globules within cell wall. Patent US498208-B; 1976.

22. Bishop JR, Nelson G, Lamb J. Microencapsulation in yeast cells. J Microencapsul. 1998;15:761-73.

23. Souza RS, Diaz-Albiter HM, Dillon VM, Dillon RJ, Genta FA. Digestion of yeasts and beta-1,3-glucanases in mosquito larvae: physiological and biochemical considerations. PLoS ONE. 2016;11:e0151403.

24. WHO. Guidelines for laboratory and field testing of mosquito larvicides. Geneva: World Health Organization; 2005.

25. Paramera El, Karathanos VT, Konteles SJ. Yeast cells and yeast-based materials for microencapsulation. In: Gaonkar AG, Vasisht N, Khare AR, Sobel R, editors. Microencapsulation in the food industry. San Diego: Academic Press; 2014. p. 267-81.

26. Viuda-Martos M, Ruiz-Navajas Y, Fernández-López J, Pérez-Álvarez JA. Chemical composition of mandarin (C. reticulata L.), grapefruit (C. paradisi L.), lemon (C. limon L.) and orange (C. sinensis L.) essential oils. J Essent Oil Bearing Plants. 2009;12:236-43.

27. Antonella A, Trozzi A, dAlcontres S, Cotroneo A. On the genuineness of citrus essential oils. Part XLVIII. The composition of volatile fraction of some varieties of sweet orange oils. J Essent Oil Res. 1996;8:159-70.

28. Essam Abdel SS, Deon Vahid C, Bruce B, Mohamed Wagdy FY, Hoda Abdel WA, Abdel Hamid M. Efficacy of botanical extracts from Callitris glaucophylla, against Aedes aegypti and Culex annulirostris mosquitoes. Trop Biomed. 2006;23:180-5.

29. Dias CN, Moraes DF. Essential oils and their compounds as Aedes aegypt L. (Diptera: Culicidae) larvicides: review. Parasitol Res. 2014;113:565-92.

30. Cheng S-S, Chang H-T, Chang S-T, Tsai K-H, Chen W-J. Bioactivity of selected plant essential oils against the yellow fever mosquito Aedes aegypti larvae. Bioresour Technol. 2003;89:99-102. 
31. Komalamisra N, Trongtokit $Y$, Rongsriyam Y, Apiwathnasorn C. Screening for larvicidal activity in some Thai plants against four mosquito vector species. Southeast Asian J Trop Med Public Health. 2005;36:1412-22.

32. Ravi Kiran S, Bhavani K, Sita Devi P, Rajeswara Rao BR, Janardhan Reddy K. Composition and larvicidal activity of leaves and stem essential oils of Chloroxylon swietenia DC against Aedes aegypti and Anopheles stephensi. Bioresour Technol. 2006:97:2481-4.

33. Tennyson S, Samraj DA, Jeyasundar D, Chalieu K. Larvicidal efficacy of plant oils against the dengue vector Aedes aegypti (L.) (Diptera: Culicidae). Middle East J Sci Res. 2013;13:64-8.

34. Cavalcanti ES, Morais SM, Lima MA, Santana EW. Larvicidal activity of essential oils from Brazilian plants against Aedes aegypti L. Mem Inst Oswaldo Cruz. 2004;99:541-4.

35. Kumar S, Warikoo R, Mishra M, Seth A, Wahab N. Larvicidal efficacy of the Citrus limetta peel extracts against Indian strains of Anopheles stephensi Liston and Aedes aegypti L. Parasitol Res. 2012;111:173-8.

36. Hemingway J, Hawkes NJ, McCarroll L, Ranson $\mathrm{H}$. The molecular basis of insecticide resistance in mosquitoes. Insect Biochem Mol Biol. 2004;34:653-65

37. Souza RS, Virginio F, Riback TIS, Suesdek L, Barufi JB, Genta FA. Microorganism-based larval diets affect mosquito development, size and nutritional reserves in the yellow fever mosquito Aedes aegypti (Diptera: Culicidae). Front Physiol. 2019;10:152.

38. WHO. Larvae source management-a supplementary measure for malaria vector control. An operational manual. Geneva: World Health Organization; 2013.

39. Carvalho FD, Moreira LA. Why is Aedes aegypti Linnaeus so successful as a species? Neotrop Entomol. 2017;46:243-55.

40. Carvalho MS, Honorio NA, Garcia LMT, Carvalho LCS. Aedes aegypti control in urban areas: a systemic approach to a complex dynamic. PLoS Negl Trop Dis. 2017;11:e0005632.

41. Rezende GL, Martins AJ, Gentile C, Farnesi LC, Pelajo-Machado M, Peixoto $A A$, et al. Embryonic desiccation resistance in Aedes aegypti: presumptive role of the chitinized serosal cuticle. BMC Dev Biol. 2008;8:82-96.
42. Moyes CL, Vontas J, Martins AJ, Ng LC, Koou SY, Dusfour I, et al. Contemporary status of insecticide resistance in the major Aedes vectors of arboviruses infecting humans. PLoS Negl Trop Dis. 2017;11:e0005625.

43. Zogo B, Tchiekoi BNC, Koffi AA, Dahounto A, Ahoua Alou LP, Dabiré RK, et al. Impact of sunlight exposure on the residual efficacy of biolarvicides Bacillus thuringiensis israelensis and Bacillus sphaericus against the main malaria vector, Anopheles gambiae. Malar J. 2019;18:55-64.

44. Silva AS, Lobo KS, Da Silva JS, Vale CFS, Tadei WP, Pineiro VCS. Influence of abiotic factors on the effectiveness of Bacillus thuringiensis israelensis (Berliner, 1911) against larvae of Aedes aegypti (Linnaeus, 1762). Rev Cubana Med Trop. 2014;66:174-90.

45. Scholte E-J, Takken W, Knols BGJ, Samson RA. Entomopathogenic fungi for mosquito control: a review. J Insect Sci. 2004;4:19-43.

46. Mains JW, Brelsfoard CL, Dobson SL. Male mosquitoes as vehicles for insecticide. PLoS Negl Trop Dis. 2015;9:e0003406.

47. Itoh $\mathrm{T}$, Kawada $\mathrm{H}$, Abe $\mathrm{A}$, Eshita $\mathrm{Y}$, Rongsriyam $\mathrm{Y}$, Igarashi A. Utilization of bloodfed females of Aedes aegypti as a vehicle for the transfer of the insect growth regulator pyriproxyfen to larval habitats. J Am Mosq Control Assoc. 1994; 10:344-7.

48. Ferreira SG, Conceicao VS, Gouveia NS, Santos GS, Santos RL, Lira AA, et al. An environmentally safe larvicide against Aedes aegypti based on in situ gelling nanostructured surfactant systems containing an essential oil. J Colloid Interface Sci. 2015;456:190-6.

49. Kavetsou E, Koutsoukos S, Daferera D, Polissiou MG, Karagiannis D, Perdikis DC, et al. Encapsulation of Mentha pulegium essential oil in yeast cell microcarriers: an approach to environmentally friendly pesticides. J Agric Food Chem. 2019:67:4746-53.

\section{Publisher's Note}

Springer Nature remains neutral with regard to jurisdictional claims in published maps and institutional affiliations.
Ready to submit your research? Choose BMC and benefit from:

- fast, convenient online submission

- thorough peer review by experienced researchers in your field

- rapid publication on acceptance

- support for research data, including large and complex data types

- gold Open Access which fosters wider collaboration and increased citations

- maximum visibility for your research: over $100 \mathrm{M}$ website views per year

At BMC, research is always in progress.

Learn more biomedcentral.com/submissions 